\title{
Strategi Pengembangan Wisata Bahari Pulau Karampuang Kabupaten Mamuju, Provinsi Sulawesi Barat
}

\author{
Development Strategy on Marine Tourism of Karampuang Island, Mamuju Regency, West \\ Sulawesi Province \\ Satriadi Lomban', Kamran Aksa ${ }^{1}$, Ilham Yahya ${ }^{1}$ \\ ${ }^{1}$ Program Studi Perencanaan Wilayah dan Kota, Fakultas Teknik, Universitas Bosowa \\ ${ }^{2}$ Program Studi Pascasarjana Perencanaan Wilayah dan Kota, Fakultas Teknik, Universitas Bosowa \\ Email: satriadilomban56@gmail.com
}

\section{Artikel info}

\section{Artikel history:}

Diterima; 17-03-2021

Direvisi: 25-03-2021

Disetujui;30-03-2021

\section{Keywords:}

Developing;

Marine tourism;

Strategy.
Abstract. This study aims to identify the significant factors in the development of marine tourism in Karampuang Island and its development strategy. This research uses quantitative and qualitative approaches. To determine the factors that have a significant effect on the development of the Karampuang Island Marine Tourism Object, the chi square analysis tool is used, while the analysis SWOT is used to formulate a strategy for the development of the Karampuang Island Marine Tourism Object. Based on the results of the ChiSquare test, it is found that the variables of tourism support facilities, safety and comfort, and accessibility do not have a significant effect on the development of the Karampuang Island Marine Tourism Object, while the variables of tourist attraction and information and promotion are the most significant factors. The strategy for developing the Karampuang Island Marine Tourism Object is improving tourism facilities and infrastructure, increasing the role of the government and private sector, increasing tourism information and promotion, improving the quality of human resources (HR), utilizing the potential of tourist attractions, and environmental preservation.

\begin{abstract}
Abstrak. Penelitian ini bertujuan untuk mengidentifikasi faktor-faktor apa saja yang signifikan dalam pengenbangan wisata bahari pulau Karampuang serta strategi pengembangannya. Penelitian ini menggunakan pendekatan kuantitatif dan kualitatif (deskriptif). Untuk mengetahui faktor yang berpengaruh signifikan terhadap pengembangan Obyek Wisata Bahari Pulau Karampuang digunakan alat analisis chi kuadrat (chi square), sedangkan analisis (SWOT) digunakan untuk merumuskan strategi pengembangan Obyek Wisata Bahari Pulau Karampuang. Berdasarkan hasil uji Chi-Square diperoleh bahwa variabel sarana penunjang wisata, keamanan dan kenyamanan, serta aksesibilitas tidak berpengaruh signifikan terhadap pengembangan Obyek Wisata Bahari Pulau Karampuang, sedangkan variabel daya tarik wisata dan informasi dan promosi merupakan faktor yang paling berpengaruh signifikan. Adapun startegi pengembangan Obyek Wisata Bahari Pulau Karampuang adalah meningkatkan sarana dan prasarana parwisata, peningkatan peran pemerintah dan swasta, peningkatan informasi dan promosi wisata, peningkatan kualitas sumber daya manusia (SDM), memanfaatkan potensi dayatarik objek wisata, serta pelestarian lingkungan.
\end{abstract}

Coresponden author: Email: satriadilomban56@gmail.com

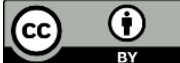

artikel dengan akses terbuka dibawah lisensi CC BY -4.0 


\section{PENDAHULUAN}

Pariwisata merupakan salah satu sektor yang potensial untuk dikembangkan oleh setiap daerah, hal ini dikarenakan setiap daerah memiliki obyek pariwisata yang dapat dikelola oleh pemerintah sebagai upaya menarik wisatawan untuk berkunjung ke daerah tersebut. Undang-Undang Republik Indonesia Nomor 10 tahun 2009 tentang kepariwisataan yang tertera dalam pasal 3 dan 4 menjelaskan bahwasanya kepariwisataan berfungsi memenuhi kebutuhan jasmani, rohani, dan intelektual setiap wisatawan dengan rekreasi dan perjalanan serta meningkatkan pendapatan negara untuk mewujudkan kesejahteraan rakyat, sedangkan tujuan pariwisata sendiri yaitu meningkatkan pertumbuhan ekonomi, meningkatkan kesejahteraan rakyat, menghapus kemiskinan, mengatasi pengangguran, melestarikan alam, lingkungan dan sumber daya, memajukan kebudayaan, mengangkat citra bangsa, memupuk rasa cinta tanah air (Khoiriyah, 2018).

Sektor pariwisata sebagai suatu kegiatan ekonomi memiliki mata rantai yang sangat panjang sehingga banyak menampung kesempatan kerja bagi masyarakat sekitarnya yang selanjutnya akan menyebabkan pendapatan masyarakat meningkat dari hasil penjualan barang dan jasa melalui usaha restoran, hotel, biro perjalanan, penjualan barang cinderamata dan sebagainya. Semakin banyak wisatawan yang datang maka akan semakin banyak devisa yang diterima dan pada akhirnya akan mendorong pembangunan sarana dan prasarana wisata lainnya (Spillane, 1989). Pemanfaatan potensi alam dan budaya Indonesia sebagai daya tarik wisata tidak dapat dipungkiri telah memberikan manfaat dan keuntungan di berbagai bidang. Peningkatan ekonomi dengan ketersediaan lapangan kerja bagi masyarakat Indonesia adalah manfaat yang paling jelas terlihat dari pengembangan pariwisata (Pratama dan Kinseng, 2013; Sharpley, 2009; Tosun, 2000). Dengan manfaat ini, target kesejahteraan masyarakat dapat tercapai yang pada akhirnya menuju masyarakat yang sejahtera dari sisi ekonomis. Menurut Yoeti (2008:106), perencanaan yang baik merupakan salah satu syarat keberhasilan pengembangan pariwisata di suatu daerah. Oleh karena itu, agar kontribusi potensi kepariwisataan yang dimiliki dapat dioptimalkan maka yang harus dilakukan adalah menentukan tujuan kepariwisataan dalam rangka mencapai tujuan tersebut.

Salah satu sumber potensial Pendapatan Asli Daerah (PAD) adalah sektor pariwisata. Pengembangan sektor pariwisata daerah Kabupaten Mamuju di dukung Undang-Undang No 10 Tahun 2009 tentang kepariwisataan yang menyebutkan keberadaan obyek wisata pada suatu daerah akan sangat menguntungkan, antara lain meningkatkan pertumbuhan ekonomi, meningkatkan kesejahteraan masyarakat, melestarikan alam dan lingkungan, memperkukuh jati diri bangsa dan memupuk rasa cinta tanah air. Dalam konteks pengembangan Kepariwisataan Nasional, Provinsi Sulawesi Barat secara umum dan Kabupaten Mamuju secara khusus dari sisi produk wisata, menyimpan sejumlah besar potensi sumberdaya wisata yang cukup memikat. Provinsi Sulawesi Barat memiliki potensi kepariwisataan yang sangat potensial untuk dikembangkan dan mendapat perhatian dalam proses perencanaan serta pembangunannya.

Pulau Karampuang yang terletak di Desa Karampuang, Kecamatan Mamuju, Kabupaten Mamuju, Provinsi Sulawesi Barat deangan luas wilayah sebesar 6,37 km2 dengan jumlah penduduk yang mencapai 3.990 jiwa, memiliki potensi sumberdaya pesisir laut yang cukup besar dengan satu-satunya destinasi wisata bahari yang paling diminati oleh masyarakat yang memiliki daya tarik keindahan terumbu karang mulai dari soft coral hingga hard coral serta keanekaragaman biota laut di dalamnya, Pulau Karampuang juga merupakan salah satu tempat yang tepat dalam pemilihan lokasi untuk rekreasi karena Pulau Karampuang tersebut jauh dari kebisingan kota juga nyaman untuk menikmati keindahan dari Pulau Karampuang, daya tarik dan potensi Obyek Wisata Pulau Karampuang menjadi salah satu aset wisata bahari dalam peningkatan pendapatan asli daerah (PAD) di Kabupaten Mamuju.

Berdasarkan kondisi eksisting yang ada, kenyataan yang terjadi saat ini objek wisata yang ada di Pulau Karampuang, Kabupaten Mamuju belum di tata dengan rapi, sarana penunjang wisata yang belum memadai serta kurangnya informasi dan promosi tentang keberadaan Obyek Wisata Pulau Karampuang dan juga masih belum optimalnya potensi pengembangan parwisata di Pulau Karampuang, akses menuju pulau masih di tangani oleh masyarakat setempat yang memiliki perahu mesin yang tidak setiap saat menyediakan jasanya untuk mengantar para wisatawan yang ingin pergi ke objek wisata Pulau Karampuang. Waktu yang di tempuh 15-20 menit dengan perjalaan kurang lebih sejauh $3 \mathrm{~km}$ dari dermaga pelabuhan Mamuju menuju objek wisata Pulau Karampuang. Oleh karena itu, dilakukan penelitian "Strategi Pengembangan Wisata Bahari Pulau Karampuang Kabupaten Mamuju". Dengan harapan menjadikan obyek wisata Pulau Karampuang sebagai salah satu destinasi wisata unggulan di Kabupaten Mamuju dan meningkatkan nilai kontribusi terhadap pendapatan asli daerah (PAD), meningkatkan kesejahterakan masyarakat daerah dan menunjang pembangunan yang ada di daerah.

\section{METODE}

\subsection{Lokasi Penelitian}

Penelitian ini dilaksanakan di obyek wisata Pulau Karampuang yang berada pada wilayah administrasi Kabupaten Mamuju, tepatnya di Kecamatan Mamuju, Desa Karampuang. Peta lokasi penelitian dapat dilihat pada Gambar 1 


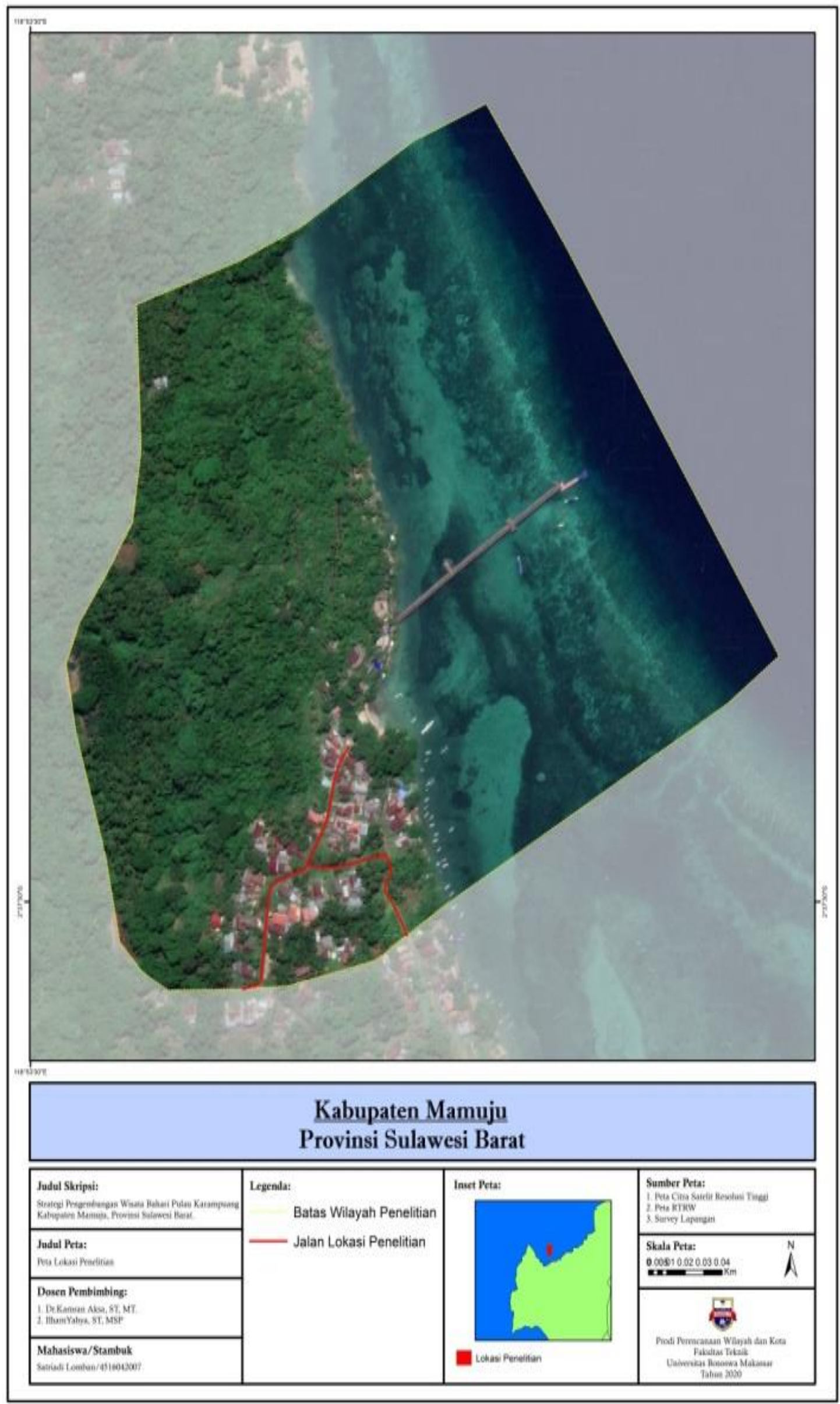

Gambar 1. Peta Pulau Karampuang 


\subsection{Jenis dan Sumber Data}

Jenis data yang digunakan pada penelitian ini ialah data kualitatif dan kuantitatif. Data kualitatif diperoleh dari hasil wawancara dengan penyebaran kuesioner. Jenis data ini meliputi kondisi sarana dan prasarana kepariwisataan, adat istiadat, pola penggunaan lahan, kondisi fisik wilayah, dan data pendukung lainnya. Adapun jenis data kuantitatif meliputi data jumlah pengunjung, jumlah penduduk, kepadatan penduduk, luas wilayah dan data pendukung lainnya.

Sumber data pada penelitian ini terdiri dari data primer dan data sekunder. Data primer dipeoleh secara langsung dengan cara survey dan observasi lapangan. Adapun data sekunder diperoleh dari instansi yang terkait seperti BPS, Dinas Pariwisata, Dinas Bappeda, Kantor Kecamatan, Kantor Desa, dan sebagainya.

\subsection{Teknik Pengumpulan Data}

Teknik pengumpulan data yang digunakan dalam penelitian ini, yaitu :

a. Observasi lapangan dengan melakukan pengamatan langsung secara sistematika mengenai fenomena yang diteliti.

b. Wawancara/Quisioner

c. Pendataan Instasional dengan mengumpulkan data melalui instansi terkait

d. Penelusuran pustaka, seperti laporan, jurnal, monografi daerah, buku, dan lainnya.

e. Dokumentasi untuk melengkapi data.

\subsection{Variabel Penelitian}

Variabel pada penelitian ini meliputi daya tarik wisata, sarana penunjang wisata, prasarana wisata, informasi dan promosi, dan aksebilitas (Tabel 1)

Tabel 1. Variabel dan Sub Variabel Penelitian

\begin{tabular}{|c|c|}
\hline Variabel & Sub Variabel \\
\hline Daya Tarik Wisata $\left(\mathrm{X}_{1}\right)$ & $\begin{array}{ll}\text { - } & \text { Data wisatawan } \\
\text { - } & \text { Daya tarik wisata }\end{array}$ \\
\hline Sarana Wisata $\left(\mathrm{X}_{2}\right)$ & $\begin{array}{l}\text { - Hotel } \\
\text { - Wisma } \\
\text { - Pedagang asongan (kios) } \\
\text { - Rumah makan (warung) } \\
\text { - Gazebo } \\
\text { - Toilet (WC) } \\
\text { - Tempat sampah } \\
\text { - Peribadatan } \\
\end{array}$ \\
\hline Keamanan dan Kenyamanan $\left(\mathrm{X}_{3}\right)$ & $\begin{array}{l}\text { - Pos jaga } \\
\text { - Petugas kebersihan } \\
\text { - Kenyamanan }\end{array}$ \\
\hline Informasi dan Promosi $\left(\mathrm{X}_{4}\right)$ & - Media promosi \\
\hline Aksesibilitas $\left(\mathrm{X}_{5}\right)$ & $\begin{array}{l}\text { - Dermaga } \\
\text { - Alur pelayaran }\end{array}$ \\
\hline
\end{tabular}

\subsection{Metode Analisis}

Metode analisis data yang digunakan dalam penelitian ini ialah sebagai berikut:

a. Analisis Chi-Square

Chi-square juga disebut sebagai Kai Kuadrat merupakan salah satu jenis uji komparatif non parametris yang dilakukan pada dua variabel dengan skala data kedua variabel ada nominal. Adapun rumus dari analisis chi-square ialah :

$$
X^{2}=\frac{\left(F_{O}-F_{h}\right)^{2}}{\left(F_{h}\right)}
$$

Keterangan :

$\mathrm{X}^{2}=$ Nilai Chi-Square

$\mathrm{F}_{\mathrm{h}}=$ Frekuensi yang diharapkan

$\mathrm{F}_{0}=$ Frekuensi yang diperoleh/diamati

Untuk mengetahui frekuensi yang diharapkan (Fn) pada masing-masing frekuensi menurut baris dan kolom, jumlah masing-masing sub bagian dan jumlah keseluruhan. Selanjutnya dapat dimasukkan ke dalam rumus sebagai berikut: 


$$
F_{h}=\frac{\left(n_{f b}-n_{f k}\right)^{2}}{N}
$$

Keterangan:

$\mathrm{F}_{\mathrm{h}}=$ Frekuensi yang diharapkan

$\mathrm{n}_{\mathrm{fb}}=$ Jumlah frekuensi masing-masing baris

$\mathrm{n}_{\mathrm{fk}}=$ Jumlah frekuensi masing-masing kolom

\section{b. Analisis SWOT}

Analisis SWOT didasarkan pada logika untuk memaksimalkan kekuatan (strenght) dan peluang (opportunities) namun secara bersamaan dapat meminimalkan kelemahan (weakness) dan ancaman (treath). Selanjutnya dilakukan evaluasi terhadap faktor internal, yaitu semua kekuatan dan kelemahan yang dimiliki obyek wisata Pantai Jikumerasa. penentuan indikator peluan dan ancaman disusun berdasarkan tujuan dalam membuat strategi pengembangan obyek wisata bahari Pulau Karampuang.

Model ananlisis SWOT

- Pembobotan tetap menggunakan skala 1 (sangat penting) hingga 0 (tidak penting), akan tetapi penentuan nilai skala untuk masing-masing situasi total berjumlah 1 dengan cara

- Urutkan fkator situasi berdasarkan skala prioritas (SP) (tetinggi nilainya 16 dari $4 \mathrm{X} 4$, urutkan 2 nilainya 3 X $4=12$ dan terendah nilai dqri 1 X 4) lalu kalikan dengan konstanta (K) nilai tertinggi 4

- Peringkat tetap menggunakan skala 1 (rendah - 4 (tinggi) untuk kekuatan dan peluang. Sedangkan skala 4 (rendah) - 1 (tinggi) untuk kelemahan dan ancaman. Namun jika tidak ada perbandingan, maka nilai skala ditentukan berdasarkan prioritas dari masing-masing situasi (misalnya berdasarkan prioritas dari masing-masing situasi (misalnya skala 4 untuk peluang yang paling tinggi).

- Nilai tertinggi untuk bobot $\mathrm{x}$ peringkat adalah $1-2$ (kuat) dan terendah adalah $0-1$ (lemah)

\section{HASIL DAN PEMBAHASAN}

\subsection{Analisis Faktor-Faktor yang Berpengaruh terhadap Pengembangan Obyek Wisata Bahari Pulau Karampuang}

Hasil analisis statistik dengan uji chi-square antara variabel independen dan variabel dependen (bivariate) dapat dilihat pada tabel berikut ini:

\subsubsection{Pengaruh Daya Tarik Wisata $\left(X_{1}\right)$ terhadap Pengembangan Obyek Wisata Pulau Karampuang}

Tabel 2. Pengaruh Daya Tarik Wisata $\left(\mathrm{X}_{1}\right)$ terhadap Pengembangan Obyek Wisata Pulau Karampuang

\begin{tabular}{|c|c|c|c|c|c|c|c|c|c|}
\hline \multirow{2}{*}{$\mathbf{Y}$} & \multirow{2}{*}{$\mathbf{X}$} & \multicolumn{2}{|c|}{$X$} & \multirow{2}{*}{$\sum$} & \multicolumn{2}{|c|}{ Fh } & \multicolumn{2}{|c|}{$\mathrm{X}^{2}$} & \multirow{2}{*}{$\sum$} \\
\hline & & 1 & 2 & & 1 & 2 & 1 & 2 & \\
\hline \multirow{2}{*}{ Y } & 1 & 18 & 34 & 52 & 33.8 & 18.2 & 7.39 & 13.72 & 21.10 \\
\hline & 2 & 47 & 1 & 48 & 31.2 & 16.8 & 8.00 & 14.86 & 22.86 \\
\hline$\sum$ & & 65 & 35 & 100 & & & & & \\
\hline$X^{2}$ & & & & & & & & & 43.96 \\
\hline $\mathrm{db}$ & & & & & & & & & 1.00 \\
\hline X2Tabel & & & & & & & & & 3.84 \\
\hline & Kesi & pula & & & & & erpes & & \\
\hline
\end{tabular}

Sumber : Hasil Analisis, Tahun 2020

Berdasarkan Tabel di atas, dapat dilihat bahwa presepsi dalam pengembangan pariwisata di Obyek Wisata Bahari Pulau Karanpuang menurut uji Chi Kuadrat berpengaruh terhadap aspek Daya Tarik wisata. Untuk mengukur tingkat presepsi dalam pengembangan pariwisata di Obyek Wisata Pulau Karampuang terhadap aspek daya tarik wisata maka selanjutnya dilakukan uji kontigensi dimana:

$$
\begin{aligned}
\mathrm{C} & =\sqrt{\frac{\mathrm{X}^{2}}{\mathrm{~N}+\mathrm{X}^{2}}} \\
\mathrm{C} & =\sqrt{\frac{43,96^{2}}{100+43,96^{2}}} \\
& =0,55 \text { ( Pengaruh Sedang ) }
\end{aligned}
$$




\subsubsection{Pengaruh Sarana Penunjang Wisata $\left(\mathrm{X}_{2}\right)$ terhadap Pengembangan Obyek Wisata Pulau Karampuang}

Tabel 3. Pengaruh Sarana Penunjang Wisata $\left(\mathrm{X}_{2}\right)$ terhadap Pengembangan Obyek Wisata Pulau Karampuang

\begin{tabular}{|c|c|c|c|c|c|c|c|c|c|}
\hline \multirow{2}{*}{$\mathbf{Y}$} & \multirow{2}{*}{$\mathbf{X}$} & \multicolumn{2}{|c|}{$\mathbf{X}$} & \multirow{2}{*}{$\sum$} & \multicolumn{2}{|c|}{ Fh } & \multicolumn{2}{|c|}{$\mathrm{X}^{2}$} & \multirow{2}{*}{$\sum$} \\
\hline & & 1 & 2 & & 1 & 2 & 1 & 2 & \\
\hline \multirow{2}{*}{ Y } & 1 & 19 & 33 & 52 & 16.12 & 35.88 & 0.51 & 0.23 & 0.00 \\
\hline & 2 & 12 & 36 & 48 & 14.88 & 33.12 & 0.56 & 0.25 & 0.81 \\
\hline$\sum$ & & 31 & 69 & 100 & & & & & \\
\hline $\mathrm{X}^{2}$ & & & & & & & & & 0.81 \\
\hline $\mathrm{db}$ & & & & & & & & & 1.00 \\
\hline $\mathrm{X}^{2}$ Tabel & & & & & & & & & 3.84 \\
\hline & $\sin$ & & & & & Tidal & rpen & & \\
\hline
\end{tabular}

Sumber : Hasil Analisis, Tahun 2020

Berdasarkan tabel di atas, dapat dilihat bahwa presepsi dalam pengembangan pariwisata di Obyek Wisata Pulau Karanpuang menurut uji Chi Kuadrat tidak berpengaruh terhadap aspek sarana wisata. Untuk mengukur tingkat presepsi dalam pengembangan pariwisata di Obyek Wisata Pulau Karanpuang terhadap aspek sarana wisata maka selanjutnya dilakukan uji kontigensi dimana:

$$
\begin{aligned}
C & =\sqrt{\frac{X^{2}}{N+X^{2}}} \\
C & =\sqrt{\frac{0,81^{2}}{100+0,81^{2}}} \\
& =0,03 \text { (Pengaruh Sangat Rendah) }
\end{aligned}
$$

\subsubsection{Pengaruh Keamanan dan Kenyamanan Obyek Wisata $\left(\mathbf{X}_{3}\right)$ Terhadap Pengembangan Obyek Wisata Pulau Karampuang}

\begin{tabular}{|c|c|c|c|c|c|c|c|c|c|}
\hline \multirow{2}{*}{$\begin{array}{l}\mathbf{Y} \\
\mathbf{X} \\
\end{array}$} & & \multicolumn{2}{|c|}{$\mathbf{X}$} & \multirow{2}{*}{$\sum$} & \multicolumn{2}{|c|}{ Fh } & \multicolumn{2}{|c|}{$\mathrm{X}^{2}$} & \multirow{2}{*}{$\sum$} \\
\hline & $x$ & 1 & 2 & & 1 & 2 & 1 & 2 & \\
\hline \multirow{2}{*}{$\mathrm{Y}$} & 1 & 33 & 19 & 52 & 32.24 & 19.76 & 0.02 & 0.03 & 0.00 \\
\hline & 2 & 29 & 19 & 48 & 29.76 & 18.24 & 0.02 & 0.03 & 0.05 \\
\hline$\sum$ & & 62 & 38 & 100 & & & & & \\
\hline $\mathrm{X}^{2}$ & & & & & & & & & 0.05 \\
\hline $\mathrm{db}$ & & & & & & & & & 1.00 \\
\hline X2Tabel & & & & & & & & & 3.84 \\
\hline \multicolumn{4}{|c|}{ Kesimpulan } & & \multicolumn{4}{|c|}{ Tidak Berpengaruh } & \\
\hline
\end{tabular}

Tabel 4. Pengaruh Keamanan dan Kenyamanan Obyek Wisata $\left(\mathrm{X}_{3}\right)$ terhadap Pengembangan Obyek Wisata Pulau Karampuang

Sumber : Hasil Analisis, Tahun 2020

Berdasarkan Tabel di atas, dapat dilihat bahwa presepsi dalam pengembangan pariwisata di Obyek Wisata Pulau Karanpuang menurut uji Chi Kuadrat tidak berpengaruh terhadap aspek sarana wisata. Untuk mengukur tingkat presepsi dalam pengembangan pariwisata di Obyek Wisata Pulau Karanpuang terhadap aspek keamanan dan kenyamanan objek wisata maka selanjutnya dilakukan uji kontigensi dimana:

$$
\begin{aligned}
& \mathrm{C}=\sqrt{\frac{\mathrm{X}^{2}}{\mathrm{~N}+\mathrm{X}^{2}}} \\
& \mathrm{C}=\sqrt{\frac{0,05^{2}}{100+0,05^{2}}} \\
& =0,14 \text { ( Pengaruh Sangat Lemah) }
\end{aligned}
$$




\subsubsection{Pengaruh Informasi dan Promosi Wisata $\left(X_{4}\right)$ Terhadap Pengembangan Obyek Wisata Pulau Karampuang}

Tabel 5. Pengaruh Informasi dan Promosi Wisata $\left(\mathrm{X}_{4}\right)$ terhadap Pengembangan Obyek Wisata Pulau Karampuang

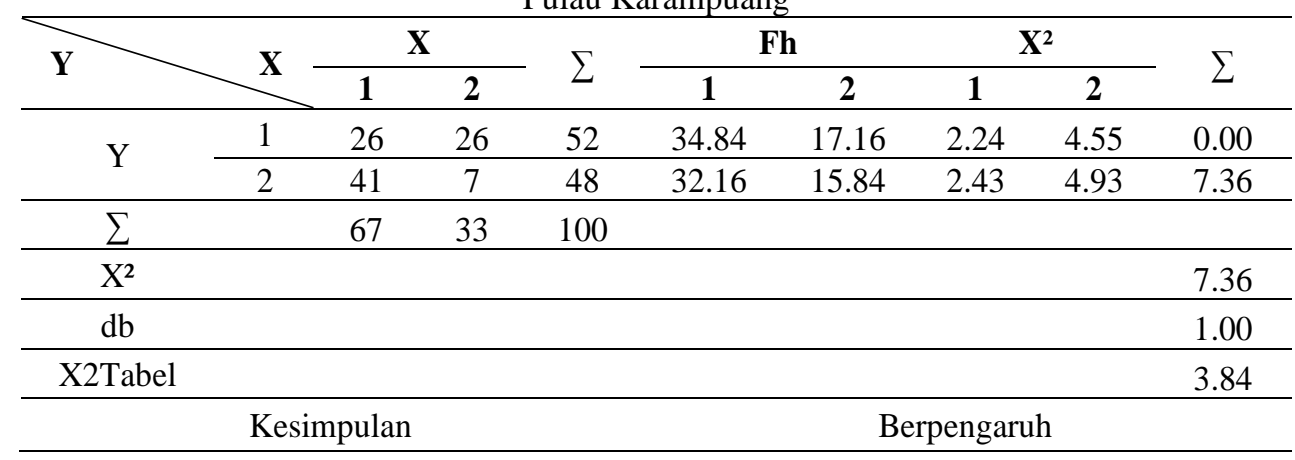

Sumber : Hasil Analisis, Tahun 2020

Berdasarkan hasil tabel di atas, dapat dilihat bahwa presepsi dalam pengembangan pariwisata di Obyek Wisata Pulau Karanpuang menurut uji Chi Kuadrat berpengaruh terhadap aspek informasi dan promosi objek wisata. Untuk mengukur tingkat presepsi dalam pengembangan pariwisata di Obyek Wisata Pulau Karanpuang terhadap aspek informasi dan promosi objek wisata maka selanjutnya dilakukan uji kontigensi dimana:

$$
\begin{aligned}
\mathrm{C} & =\sqrt{\frac{\mathrm{X}^{2}}{\mathrm{~N}+\mathrm{X}^{2}}} \\
\mathrm{C} & =\sqrt{\frac{7.36^{2}}{100+7,36^{2}}} \\
& =0,26 \text { ( Pengaruh Lemah) }
\end{aligned}
$$

\begin{tabular}{|c|c|c|c|c|c|c|c|c|c|}
\hline \multirow{2}{*}{$\frac{\mathbf{Y}}{\mathbf{X}}$} & & \multicolumn{2}{|c|}{$\mathbf{X}$} & \multirow{2}{*}{$\sum$} & \multicolumn{2}{|c|}{ Fh } & \multicolumn{2}{|c|}{$\mathbf{X}^{2}$} & \multirow{2}{*}{$\sum$} \\
\hline & & 1 & 2 & & 1 & 2 & 1 & 2 & \\
\hline \multirow{2}{*}{$\mathrm{Y}$} & 1 & 12 & 40 & 52 & 11.44 & 40.56 & 0.03 & 0.01 & 0.00 \\
\hline & 2 & 10 & 38 & 48 & 10.56 & 37.44 & 0.03 & 0.01 & 0.04 \\
\hline$\sum$ & & 22 & 78 & 100 & & & & & \\
\hline$X^{2}$ & & & & & & & & & 0.04 \\
\hline $\mathrm{db}$ & & & & & & & & & 1.00 \\
\hline X2Tabel & & & & & & & & & 3.84 \\
\hline
\end{tabular}

\subsubsection{Pengaruh Aksesibilitas Wisata $\left(\mathrm{X}_{5}\right)$ Terhadap Pengembangan Obyek Wisata Pulau Karampuang}

Tabel 6. Pengaruh Aksesibiltas Wisata $\left(\mathrm{X}_{5}\right)$ terhadap Pengembangan Obyek Wisata Pulau Karampuang

Sumber : Hasil Analisis, Tahun 2020

Berdasarkan Tabel di atas, dapat dilihat bahwa presepsi dalam pengembangan pariwisata di Obyek Wisata Pulau Karanpuang menurut uji Chi Kuadrat berpengaruh terhadap aspek aksesibilitas objek wisata. Untuk mengukur tingkat presepsi dalam pengembangan pariwisata di Obyek Wisata Pulau Karanpuang terhadap aspek aksesibilitas objek wisata maka selanjutnya dilakukan uji kontigensi dimana:

$$
\begin{aligned}
C & =\sqrt{\frac{X^{2}}{N+X^{2}}} \\
C & =\sqrt{\frac{0,04^{2}}{100+0,04^{2}}} \\
& =0,02 \quad(\text { Pengaruh Sangat Lemah ) }
\end{aligned}
$$




\subsection{Analisis Strategi Pengembangan Obyek Wisata Pulau Karampuang}

\subsubsection{Internal Strategy Factor Analysis (IFAS)}

Tabel 7. Matriks Internal Strategy Factor Analysis (IFAS) Strategi Pengembangan Obyek Wisata Bahari Pulau Karampuang

\begin{tabular}{|c|c|c|c|c|c|}
\hline No. & Faktor Internal & SP & $\mathbf{K}$ & SP $\times \mathrm{K}$ & Bobot \\
\hline & Kekuatan : & & & & \\
\hline 1 & Memiliki sumberdaya pesisir yang cukup besar. & 12 & 3 & 36 & 0,27 \\
\hline 2 & $\begin{array}{l}\text { Lokasi yang strategis yang terletak jauh dari kebisingan } \\
\text { kota. }\end{array}$ & 8 & 3 & 24 & 0,18 \\
\hline 3 & Kondisi alam pada obyek wisata yang masih asri. & 8 & 3 & 24 & 0,18 \\
\hline 4 & $\begin{array}{l}\text { Antusiasme wisatawan yang datang ke objek wisata } \\
\text { meningkat di tiap tahunnya. }\end{array}$ & 8 & 3 & 24 & 0,18 \\
\hline \multirow[t]{2}{*}{5} & $\begin{array}{l}\text { Upaya pemerintah daerah yang cukup baik dalam } \\
\text { mempromosikan obyek wisata bahari pulau } \\
\text { karampuang. }\end{array}$ & 8 & 3 & 24 & 0,18 \\
\hline & Jumlah & 44 & 15 & 132 & \multirow[b]{2}{*}{0,16} \\
\hline 6 & $\begin{array}{l}\text { Kelemahan : } \\
\text { Sarana penunjang wisata yang masih kurang memadai. }\end{array}$ & 8 & 3 & 24 & \\
\hline 7 & $\begin{array}{l}\text { Akses menuju Obyek Wisata Bahari Pulau Karampuang } \\
\text { masih dalam kondisi kurang baik (buruk) serta kurangya } \\
\text { dukungan dari Pemerintahan Daerah. }\end{array}$ & 16 & 3 & 48 & 0,33 \\
\hline 8 & Kurangnya SDM mengenai pentingnya pariwisata. & 12 & 3 & 36 & 0,25 \\
\hline 9 & $\begin{array}{l}\text { Keterbatasan jaringan, dan moda transportasi dan } \\
\text { konektivitas antar moda untuk mendukung kemudahan } \\
\text { pergerakan wisata. }\end{array}$ & 12 & 3 & 36 & 0,25 \\
\hline & Jumlah & 48 & 12 & 144 & \\
\hline
\end{tabular}

Sumber: Hasil Analisis Tahun 2020.

Tabel 8. Matriks Nilai Skor IFAS Strategi Pengembangan Obyek Wisata Bahari Pulau

\begin{tabular}{|c|c|c|c|c|}
\hline No. & Faktor Internal & Bobot & Rating & $\begin{array}{c}\text { Bobot } \mathrm{x} \\
\text { Rating } \\
\end{array}$ \\
\hline 1 & $\begin{array}{l}\text { Kekuatan : } \\
\text { Memiliki sumber daya pesisir yang cukup besar. }\end{array}$ & 0,27 & 3 & 0,81 \\
\hline 2 & $\begin{array}{l}\text { Lokasi yang strategis yang terletak jauh dari kebisingan } \\
\text { kota. }\end{array}$ & 0,18 & 2 & 0,36 \\
\hline 3 & Kondisi alam pada obyek wisata yang masih asri. & 0,18 & 2 & 0,36 \\
\hline 4 & $\begin{array}{l}\text { Antusiasme wisatawan yang datang ke objek wisata } \\
\text { meningkat di tiap tahunnya. }\end{array}$ & 0,18 & 2 & 0,36 \\
\hline \multirow[t]{2}{*}{5} & $\begin{array}{l}\text { Upaya pemerintah daerah yang cukup baik dalam } \\
\text { mempromosikan obyek wisata bahari pulau karampuang. }\end{array}$ & 0,18 & 2 & 0,36 \\
\hline & Jumlah & & & 2,25 \\
\hline 6 & $\begin{array}{l}\text { Kelemahan : } \\
\text { Sarana penunjang wisata yang masih kurang memadai. }\end{array}$ & 0,16 & 3 & 0,48 \\
\hline 7 & $\begin{array}{l}\text { Akses menuju Obyek Wisata Pantai Papaliseran masih } \\
\text { dalam kondisi kurang baik (buruk) serta kuaranya } \\
\text { dukungan Pemerintahan Daerah. }\end{array}$ & 0,33 & 4 & 1,33 \\
\hline 8 & Kurangnya SDM mengenai pentingnya pariwisata. & 0,25 & 3 & 0,75 \\
\hline 9 & $\begin{array}{l}\text { Keterbatasan jaringan, dan moda transportasi dan } \\
\text { konektivitas antar moda untuk mendukung kemudahan } \\
\text { pergerakan wisata. }\end{array}$ & 0,25 & 3 & 0,75 \\
\hline & Jumlah & & & 3,31 \\
\hline
\end{tabular}

Sumber: Hasil Anaisis Tahun 2020. 


\subsubsection{Eksternal Strategy Factor Analysis (EFAS)}

Tabel 9. Matriks Eksternal Strategy Factor Analysis (EFAS) Strategi Pengembangan Obyek Wisata Bahari Pulau Karampuang

\begin{tabular}{|c|c|c|c|c|c|}
\hline No. & Faktor Eksternal & SP & $\mathrm{K}$ & SP $x \mathrm{~K}$ & Bobot \\
\hline 1 & $\begin{array}{l}\text { Peluang: } \\
\text { Visi (Rencana Induk Pembangunan Kepariwisataan Provinsi } \\
\text { Sulawesi Barat Tahun 2018-2025) menjadikan sebagai } \\
\text { destinasi wisata berkelas dunia, berkelanjutan, berbasis pada } \\
\text { potensi kearifan lokal, yang mendorong pembangunan daerah, } \\
\text { kesejahteraan masyarakat, menuju Sulawesi Barat maju dan } \\
\text { malaqbi. }\end{array}$ & 8 & 3 & 24 & 0,24 \\
\hline 2 & $\begin{array}{l}\text { Pembangunan industri parwisata yang digariskan dalam } \\
\text { Peraturan Pemerintah No } 50 \text { Tahun } 2011 \text { tentang } \\
\text { RIPPARNAS 2010-2025. }\end{array}$ & 8 & 2 & 16 & 0,16 \\
\hline 3 & $\begin{array}{l}\text { Diberlakukannya UU No } 32 \text { Tahun } 2004 \text { tentang otonomi } \\
\text { daerah. }\end{array}$ & 8 & 3 & 24 & 0,24 \\
\hline 4 & $\begin{array}{l}\text { Meningkatkan pendapatan masyarakat dan pendapatan asli } \\
\text { daerah (PAD). }\end{array}$ & 12 & 3 & 36 & 0,36 \\
\hline & Jumlah & 36 & 9 & 100 & \\
\hline 5 & $\begin{array}{l}\text { Ancaman: } \\
\text { Terjadinya Abrasi Pantai. }\end{array}$ & 16 & 3 & 48 & 0,30 \\
\hline 6 & Terjadinya degradasi lingkungan. & 12 & 3 & 36 & 0,23 \\
\hline 7 & Meningkatnya tingkat kriminalitas/konflik sosial. & 12 & 3 & 36 & 0,23 \\
\hline 8 & $\begin{array}{l}\text { Persaingan yang erat antara daerah tujuan wisata yang dimana } \\
\text { semakin banyknya daerah daerah yang mengembangkan } \\
\text { parwisata baik di dalam maupun luar negeri yang menambah } \\
\text { ketatnya persaingan. }\end{array}$ & 12 & 3 & 36 & 0,23 \\
\hline & Jumlah & 40 & 9 & 156 & \\
\hline
\end{tabular}

Tabel 10. Matriks Nilai Skor EFAS (Eksternal Factor Evaluation) Strategi Pengembangan Obyek Wisata Bahari Pulau Karampuang.

\begin{tabular}{|c|c|c|c|c|}
\hline No. & Faktor Eksternal & Bobot & Rating & $\begin{array}{l}\text { Bobot } \mathrm{x} \\
\text { Rating }\end{array}$ \\
\hline 1 & $\begin{array}{l}\text { Peluang: } \\
\text { Visi dari (Rencana Induk Pembangunan Kepariwisataan Provinsi } \\
\text { Sulawesi Barat Tahun 2018-2025) menjadikan sebagai destinasi } \\
\text { wisata berkelas dunia, berkelanjutan, berbasis pada potensi } \\
\text { kearifan lokal, yang mendorong pembangunan daerah, } \\
\text { kesejahteraan masyarakat, menuju Sulawesi Barat maju dan } \\
\text { malaqbi. }\end{array}$ & 0,24 & 2 & 0,48 \\
\hline 2 & $\begin{array}{l}\text { Pembangunan industri parwisata yang digariskan dalam } \\
\text { Peraturan Pemerintah No } 50 \text { Tahun } 2011 \text { tentang RIPPARNAS } \\
\text { 2010-2025. }\end{array}$ & 0,16 & 4 & 0,64 \\
\hline 3 & $\begin{array}{l}\text { Diberlakukannya UU No } 32 \text { Tahun } 2004 \text { tentang otonomi } \\
\text { daerah. }\end{array}$ & 0,24 & 3 & 0,72 \\
\hline \multirow[t]{2}{*}{4} & $\begin{array}{l}\text { Meningkatkan pendapatan masyarakat dan pendapatan asli } \\
\text { daerah (PAD). }\end{array}$ & 0,36 & 3 & 1,08 \\
\hline & Jumlah & & & 2,92 \\
\hline 5 & $\begin{array}{l}\text { Ancaman: } \\
\text { Terjadinya Abrasi Pantai }\end{array}$ & 0,30 & 4 & 0,12 \\
\hline 6 & Terjadinya degradasi lingkungan. & 0,23 & 3 & 0,69 \\
\hline 7 & Meningkatnya tingkat kriminalitas/konflik sosial. & 0,23 & 3 & 0,69 \\
\hline \multirow[t]{2}{*}{8} & $\begin{array}{l}\text { Persaingan yang erat antara daerah tujuan wisata yang dimana } \\
\text { semakin banyknya daerah daerah yang mengembangkan } \\
\text { parwisata baik di dalam maupun luar negeri yang menambah } \\
\text { ketatnya persaingan. }\end{array}$ & 0,23 & 3 & 0,69 \\
\hline & Jumlah & & & 2,82 \\
\hline
\end{tabular}


Alternatif strategi dalam pengembangan Obyek Wisata Bahari Pulau Karampuang dapat dirumuskan dengan pendekatan analisis SWOT. Analisis matriks SWOT merupakan langkah selanjutnya setelah dilakukan analisis IFAS dan EFAS, yakni dengan mencocokan faktor-faktor internal berupa kekuatan dan kelemahan dengan faktorfaktor eksternal berupa peluang dan ancaman yang berpengaruh dalam pengembangan Obyek Wisata Pulau Karampuang. Untuk Lebih jelasnya matriks SWOT dalam perumusan strategi pengembangan Obyek Wisata Bahari Pulau Karampuang dapat sebagai berikut :

Tabel 11. Matriks SWOT Obyel Wisata Bahari Pulau Karampuang

Kekuatan (S) Kelemahan (W)

1. Memiliki sumberdaya pesisir dan dayatarik yang cukup besar.

2. Lokasi yang strategis yang terletak jauh dari kebisingan kota

3. Kondisi alam pada obyek wisata yang masih asri

4. Antusiasme wisatawan yang datang ke objek wisata

5. Meningkat di tiap tahunnya

6. Upaya pemerintah daerah yang cukup baik dalam mempromosikan obyek wisata bahari pulau karampuang

1. Sarana penunjang wisata yang masih kurang memadai.

2. Akses menuju Obyek Wisata Pantai Papaliseran masih dalam kondisi kurang baik (buruk) serta kuaranya dukungan Pemerintahan Daerah

3. Kurangnya SDM mengenai kesadaran pentingnya pariwisata.

4. Keterbatasan jaringan, dan moda transportasi dan konektivitas antar moda untuk mendukung kemudahan pergerakan wisata.

5. Kurangnya perawatam terhadap objek wisata dan fasilitas yang sudah ada.

6. Keamanan dan kenyamanan yang belum maksimal di obyek wisata.

7. Tidak adanya atraksi budaya yang disuguhkan obyek wisata pulau karampuang

\section{Peluang (O)}

1. Visi dari (Rencana Induk Pembangunan Kepariwisataan Provinsi Sulawesi Barat Tahun 2018-2025) menjadikan sebagai destinasi wisata berkelas dunia, berkelanjutan, berbasis pada potensi kearifan lokal, yang mendorong pembangunan daerah, kesejahteraan masyarakat, menuju Sulawesi Barat maju dan malaqbi.

2. Pengembangan industri parwisata yang digariskan dalam Peraturan Pemerintah No 50 Tahun 2011 tentang RIPPARNAS 2010-2025

3. Diberlakukannya UU No 32 Tahun 2004 tentang otonomi daerah.

4. Meningkatkan pendapatan masyarakat dan pendapatan asli daerah (PAD).

Strategi S-O (Aggresive Strategies)

1. Menerapkan /menjalankan kebijakan pemerintah daerah dalam hal pengembangan obyek parwisata.

2. Mempertahankan dan memelihara sumber daya pesisir agar minat wiasatawan yang berkunjung akan terus bertambah.

3. Kerjasama dengan instansi terkait termaksud biro perjalanan perjalanan dalam mempromosikan Obyek Wisata Bahari Pulau Karampaung.

4. Peningkatan kontribusi parwisata terhadap kualitas dan kuantitas sumber daya manusia sehingga dalam pembangunan indusri parwisata dapat bejalan dengan optimal sesuai dengan Peraturan Pemerintah No 50 Tahun 2011 tentang RIPPARNAS 2010-2025.

5. Peningkatan peran pemrintah daerah sebagia eksekutor pembuatan kebijakan dalam upaya peningkatan pengambangan obyek wisata.

\section{Ancaman (T)}

1. Terjadinya Abrasi Pantai.

2. Terjadinya degradasi lingkungan.

3. Meningkatnya tingkat kriminalitas/konflik sosial

4. Persaingan yang erat antara daerah tujuan wisata yang dimana semakin banyknya daerah daerah yang mengembangkan parwisata baik di dalam maupun luar negeri yang menambah ketatnya persaingan

\section{Strategi W-O (Turn Arround Strategies)}

1. Meningkatkan sarana dan prasarana penunjang wisata untuk menarik minat wisatawan/pengunjung untuk berkunjung di Obyek Wisata Pulau Karampuang.

2. Pengadaan akses khusus kapal bagi wisatawan yang akan berkunjung ke obyek wisata untuk pengembangan industri pawisata yang berkelanjutan.

3. Mengadaka pelatihan bagi pengelolah keparwisataan serta pembinaan dalam mengembangkan dan pengelolaan industri wisata di Pulau Karampuang.

4. Meningkatkan promosi dengan berbagai media promosi dengan pemanfaatan teknologi informasi yang dan bekerja sama dengan instansi terkait termaksud biro perjalanan dalam memperomosikan Obyek Wisata Bahari Pulau Karampuang.

5. Menjaga dan meningkatkan kesadara akan keindahan dan kebersihan obyek wisata dengan peraturan yang telah di tetapkan oleh pemerintahan 
daerah atau dari pihak pengeloala sehingga terwujudnya lingkungan yang bersih dan asri.

6. Peningkatan peran pemerintah daerah sebagai eksekutor pembuat kebijakan dalam mengawal pengembangan objek parwisata.

7. Memanfaatkan potensi dayatarik objekwisata sebagai kawasan parwisata unggulan dengan tetap memperhatikan sektor lingkungan.

8. Mengembangankan industri parwisata dengan memanfaatkan lapangan kerja masyarakat lokal untuk diversifikasi produk wisata dalam Obyek Wisata Bahari Pulau Karampuang

Strategi S-T (Divensification Strategies)

1. Sosialisasi dan konsistensi terhadap peraturan lingkungan hidup.

2. Pembuatan pemecah ombak atau penanaman mangrove di pantai sekitar obyek wisata.

3. Pemeliharaan akan dayatarik yang masih alami yang di tawarkan oleh Pulau Karampuang.

4. Mengedukasi kepada masyarakat untuk menjaga kestabilan lingkungan yang terdapat pada obyek wisata Pulau Karampuang.
Strategi W-T (Defensive Strategies)

1. Pembenahan dan pembangunan sarana penunjang di Obyek wisata Pulau Karampuang.

2. Meningkatkan SDM dalam hal keparwisataan dan melibatkan pihak swasta, pemerintah dan masyarakat dalam manajemen dan pengelolaan serta pembangunan sarana penunjang wisata do Obyek Wisata Pulau Karampuang.

3. Mengesploitasi potensi dayatarik wisata Pulau Karampuang dengan tetap memperhatikan sektor lingkungan.

4. Pemberdayaan masyarakat dalam pengenbangan obyek wisata Pulau Karampuang serta pemerataan hasil pembangunan bagi seluruh masyarakat guna menekan tingkat kriminalitas yang terjadi.

\section{Sumber : Hasil Analisis Tahun 2020}

\section{KESIMPULAN}

Berdasarkan hasil penelitian yang telah dianalisis terkait Strategi Pengembangan Obyek Wisata Bahari Pulau Karampuang Kabupaten Mauju, dapat disimpulkan bahwa sarana penunjang wisata, keamanan dan kenyamanan, serta aksesibilitas tidak berpengaruh signifikan terhadap pengembangan Obyek Wisata Bahari Pulau Karampuang, sedangkan variabel daya tarik wisata dan informasi dan promosi merupakan faktor yang paling berpengaruh signifikan. Adapun startegi pengembangan Obyek Wisata Bahari Pulau Karampuang adalah meningkatkan sarana dan prasarana parwisata, peningkatan peran pemerintah dan swasta, peningkatan informasi dan promosi wisata, peningkatan kualitas sumber daya manusia $(S D M)$, memanfaatkan potensi dayatarik objek wisata, serta pelestarian lingkungan.

\section{DAFTAR PUSTAKA}

Khoiriyah, B. A. (2018). Strategi Pengembangan Fasilitas Wisata Cemara Sewu Tulungagung Untuk Menarik Wisatawan.

Pratama dan Kinseng. (2013). Dampak Pengembangan Pariwisata dan Sikap Nelayan di Desa Pangandaran. Jurnal Penyuluhan, 9(1): 10-17

Sharpley, R. (2009). Tourism, Development and the Environment: Beyond Sustainability. London: Earthscan: 181 Spillane, J. (1989). Pariwisata Indonesia, Sejarah dan Prospeknya. Kanisius: Yogyakarta.

Tosun, C. (2000). Limits to Community Participation in The Tourism Development Process in Developing Countries. Tourism Management. 21(6): 613-633.

Undang-Undang Republik Indonesia Nomor 10 Tahun 2009 tentang Kepariwisataan. diakses pada https://jdih.kemenkeu.go.id/fullText/2009/10TAHUN2009UU.HTM

Yoeti, O.A (2008) Perencanaan dan Pengembangan Pariwisata. Pradnya Paramita: Jakarta.. 